\title{
The Comparative Analysis of Adsorbents Suitable for Thermal Desalination System
}

\author{
S. Ntsondwa, V. Msomi, M. Basitere, and Z. Mdletshe
}

\begin{abstract}
Adsorption desalination is a newly developed desalination method that features adsorption desorption cycle. This cycle has two major components the adsorbent and adsorbate. The adsorbent is a material that has hydrophilic and hydrophobic properties, it adsorbs (attract) and desorbs (rejects) the adsorbate of its surface area. The two properties are triggered by temperature change; the hydrophilic property is activated when the adsorbent is exposed to cold temperature conditions and hydrophobic is activated when exposed to hot temperature conditions. Incorporating the adsorption desalination $(\mathrm{AD})$ cycle increase the water vapour uptake rate and that yield more desalination water over short period of time. There are three specific adsorbents used adsorbents; silica gel $\left(\mathrm{SiO}_{2}\right)$; activated alumina oxide $\left(\mathrm{Al}_{2} \mathrm{O}_{3}\right)$ and molecular sieve zeolite. The applications for these adsorbents depend on their native sorption properties e.g. its porosity and surface area. This study comprehensively reviews what is currently available on literature related to adsorption process and analyse the performance of three adsorbents analysed through a similar adsorption process.
\end{abstract}

Keywords-Adsorbents, desorption and desorption cycle, Isotherm affinity, Desalination processes.

\section{INTRODUCTION}

Access to potable water is essential for human development and to economic activities of a country. Industry, ranches, and the general population all need accessible clean and freshwater [3]. As the earth's population continues to grow and develop, the limited freshwater resource becomes increasingly scarce [4]. There are various factors leading to the now reported, on-going global water crises. Climate change and population growth are the factors making it difficult for water supply to meet water demands [19]. However, the highest percentage of water is seawater. Awareness to developing water shortage has prompted a higher enthusiasm for seawater desalination, which is regarded as an option to take care of the water deficiency issue [13].

Western Cape region in South Africa can highly relate in this matter, between mid-2017 up to mid-2018 the water crisis peaked. Desalination process can be a solution to water scarcity. Nevertheless, the biggest disadvantage to traditional techniques of desalination is that they are costly to maintain.

The history confirms that due to its high capital and energy costs, desalination of seawater has been the most expensive way to produce commercial drinking water. [12]. Thus, there is

Manuscript received October 10, 2019. S. Ntsondwa is with the Cape Peninsula University of Technology,. therefore, an ambition to discover new desalination methods that consume less chemicals and heat energy [9].

Industrial sector and academic fraternity have embarked on exploring the ocean as an alternative solution to address water scarcity [9]. The abundant seawater converted into freshwater throughout desalination. The desalination method accomplished by separating salt from seawater [5]. There are so many desalination common methods to be used, like reverse osmosis or thermal desalination [7].

In literature there are so many studies conducted to find a better desalination technique, which utilize low energy. However, Ng et al., [17] came up with a far better idea of the new low cost thermal desalination process by incorporating the adsorption desalination cycle with two major components, the adsorbent and the adsorbent. [17].

Adsorption desalinating process is the promising method that can be used, it is environmental friendly and utilise low temperature [16]. Nonetheless, a commercially established adsorption process requires the availability of an acceptable adsorbent in large quantities at an economic cost [15]. This has attracted the attention of many researchers into improving adsorption process by finding proper conditions to be operated at; hence it provides confidence in improvement of desalination and economy [15].

Adsorption is the adherence or attachment of gas, fluid or dissolved organic molecules to the solid or sometimes liquid layer [11]. Advantages of Adsorption desalination include low maintenance cost, environmental friendly, low corrosion and fouling rate, produce high grade potable water, utilise low temperature waste heat and no pre-treatment of feed water required [21].

Adsorption has various types that include physisorption and chemisorption. [25]. Physisorption operates using Van de Waal interaction and its molecules maintain their physical structure, while chemisorption involves chemical bonds and its molecules lose its identity [25].

Adsorption happens when atoms, ions or molecules attached to the surface of a substance without entering it [10]. The surface holding molecules operate with weak bonds and can easily break. Same as in adsorption desalination process, hydration sphere surrounds the outer sphere complexes and not the inner sphere ones [10].

Fig. 1 below shows the adsorption process: 


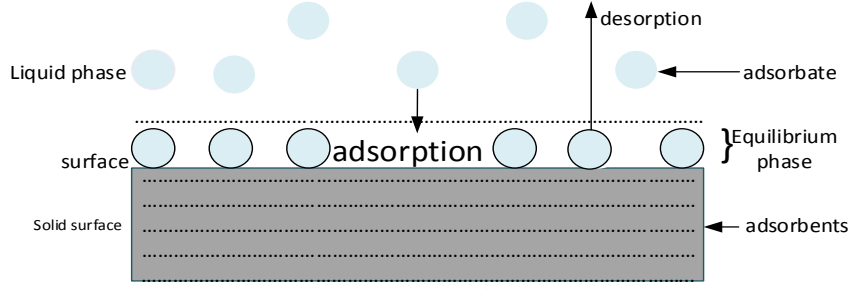

Fig. 1: Basic terms of adsorption.

Nearly all processes of adsorptive separation rely on physical adsorption instead of chemisorption, thus this is the part of the main focus of this analysis. When working on the fundamentals of adsorption, it is important to understand the difference between physical adsorption involving only comparatively weak intermolecular forces and chemisorption, which basically involves the creation of a chemical bond between the adsorbent molecule and the adsorbent layer [20]. Whereas this classification is conceptually helpful, there are many intermediate situations, and the categorization of a particular system is not always unambiguous. A more recent invention is the use of adsorption as a means of separating mixtures into two or more sources, each enhanced with a recovered valuable component [22].

Separation described as a method that converts a substance batch into two or more composite goods [12]. This method is hard to attain because it is the reverse of mixing, a process recommended by the second thermodynamics law. As a result, separation steps often account for significant production costs in the desalination method. A mass separating agent for many separation processes triggers separation. The adsorption mass separator agent is adsorbent. Quality of the adsorbent legitimately determined by the design of the separation or purification process of adsorption [25].

Adsorbent is the substance in which adsorption occurs on or a layer that is able to adsorb other particles. It is a solid substance used to collect solute molecules from a liquid or gas [25]. They are porous solids that tie in their surface liquid or gaseous molecules. The adsorption process mostly includes what referred to as a fixed bed adsorber, where a substance like air passes through a solid adsorbent bed [10]. The adsorbent draws the undesirable particles in the air as the moisture evaporates. It helps to improve efficiency by placing various layers of these beds [18].

Generally, adsorbents are used with a radius of a certain amount in the shape of circular balls, rods or pyramids. Need to have a high affinity to abrasion, low-temperature stability, and tiny pore diameters, leading to higher exposed surface area and thus high reliability for adsorption [2]. The adsorbents must also have a special porous structure that enables rapid transportation of the gaseous vapor [2].

Activated alumina, silica gel, activated charcoal, molecular sieve carbon, sieve zeolites, and inorganic adsorbents are examples of adsorbents most of which are used [10]. Other adsorbents created and some other adsorbents such as zeolites occur naturally; each component has its properties such as porosity, porous structure, and adsorbent surface area [17].
The new system's uniqueness is in the same manner used in natural forces to produce vacuum conditions and its incorporation into a single device model where evaporation and condensation occur at appropriate locations without any external energy supply other than low energy. According to $\mathrm{Ng}$ et al., [17] it is generally possible to produce portable water with adsorption at low cost. However, it will require adsorbents that can absorb a lot of vapour and the best adhesive adsorbent is not yet known, hence it is needed to conduct a comparative analysis of a best behaving adsorbent.

This has triggered the desire for critical adsorption research and resulted in a modern adsorbent being created. The adsorption process used before was either activated carbon or silica gel adsorbents, but the ability of adsorption as a separation process was greatly improved by the production of adsorbent molecular sieve, especially polymer zeolite, which was first commercially available in the olden days. So far there has been a synthesis of large zeolite structures, several of which have proved to be valuable adsorbents and are now commercially available [10].

\section{A. Adsorbents and their characteristics}

Silica gel is an indistinct type of silicon dioxide that is chemically synthesized as tough abnormal granules or hard irregular beads [14]. The layout of a micro porous cavity offers a very high surface area. This structure provides a large-capacity silica gel desiccant. Water molecules bind to silica gels ' surface as they have lower vapor pressure compared to the surrounding water. No more adsorption comes into play if equal pressure is reached. Therefore, the higher the surrounding air humidity, the lower the amount of water adsorbed before the equilibrium was reached [14].

The unique aspect of the silica gel is the actual adsorption of water vapor in its internal pores, which has a very elevated porosity that can easily adsorb air around $800 \mathrm{~m} 2 / \mathrm{g}$, making it useful as a drying agent [8]. it has no reaction, no degradation of the substance or side effects. The silica gel has the appearance of a dry material, the composition of which remains constant, even when soaked with water vapor. Silica Gel has been one of the strong desiccant and most popular desiccants and adsorbents used in a wide range of industrial and product processes [2]

Molecular sieve zeolites are solid structure consisting of a group of minerals of silicate with uncommon industrial significance characteristics. Many happen as natural minerals, but it is the synthetic varieties, that are among the world's most commonly used sorbents, catalysts and equipment for ion exchange [1]. Zeolites can resist high pressure, are not dissolving in water or other inorganic solvents, and are not oxidizing in the air. Because they are unreactive and based on minerals that occur naturally, no damaging environmental effects thought to have. Because they are unreactive and based on minerals that occur naturally, no damaging environmental effects thought to have [24]. Molecular sieve zeolites have different classes with different thermo-physical properties and different chemical isotherm. 
Activated alumina is a white encrusted desiccant with a diameter of between 2 and $4 \mathrm{~mm}$. It has a larger surface-area-to-weight ratio compared to silica gel and displays a greater fluctuation of the adsorbed amount due to changes in ambient temperature. Activated alumina is primarily used for heatless regenerative dehumidifying equipment because of its adsorption characteristics [23].

Activated aluminum derived from aluminum hydroxide by dehydroxylating it in a manner that creates a highly porous material; this material may have a surface area significantly greater than $200 \mathrm{~m} 2 / \mathrm{g}$. the compound used as a desiccant and as a buffer for fluoride, arsenic and seleniumin drinking water. This consists of the same chemical substance as sapphire and ruby, aluminum oxide [23].

Here is a very large surface-area-to-weight ratio due to the many pore tunnels it has. [23]. Activated alumina used across the world as high quality purifying agents due to the various benefits that they render [23]. They are truly porous type of aluminium oxide that can help in removing all kinds of impurities and moisture from product, which no other substance is able to provide[15].

\section{MATERIALS AND SYSTEM DESIGN}

A lab-scale adsorption desalination system designed and constructed. A diagram of the lab testing structure is represented in Fig. 2. The system comprises of two components necessary for the cycle. The first section is the main cycle with three parts for adsorption / desorption procedures. It is made up of evaporator, reactor and condenser. The second components; is the loop of water circulation in the set-up for heat/cooling supply during adsorption-desorption process and heat recovery. Figure below; summarize the lab-scale schematic diagram:

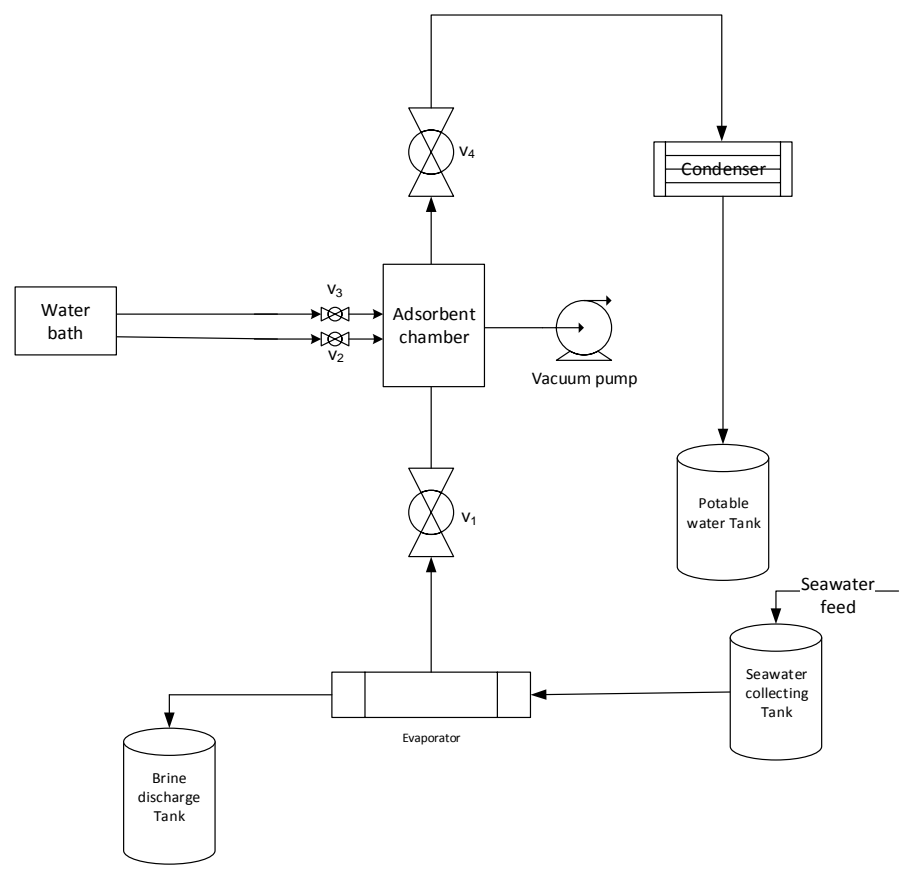

Fig. 2: A lab-scale adsorption desalination system

\section{A. Analysis of the design}

This study exclusively concentrated on the adsorption method, during the adsorption phase Just heat recovery used for the main cycle and the air loop. The cycle process includes a reactor (adsorber) in which the adsorbent is filled and the water vapor (adsorbate) is transferred and reacts with the dry adsorbent, a vapor condenser as a condensing and processing fluid and an evaporator to be added to the vaporizing reactor.

In order to maintain the pressure, the heat exchanger reactor-bed (adsorbent chamber) placed inside the acrylic vacuum chamber. The single copper coil mounted between the adsorbents inside the acrylic vacuum and linked to a water bath to keep continuous wind circumstances (heating and cooling conditions) during the adsorption-desorption phase and the adsorbent thermocouple (TC) placed in almost every corner of the packed adsorbents as a temperature sensor.

A metal mesh cover has been placed $5-8 \mathrm{~cm}$ from the bottom and top flange (reactor inlet and outlet side) with diameter holes that are smaller than the adsorbent surface area. This metal mesh creates the space between the reactor bed filled with adsorbents and the inlet of the reactor in order a vapour can be effectively transmitted and adsorbed into the adsorbent. The metal mesh plays a role function in maintaining the position of adsorbent particles.

Vacuum pump is used specifically for the purpose of air removal. A heating tape mounted to control the temperature of the cubes on the connecting pipes. Using a reading rag (0-100 $\mathrm{KPa}$ ) pressure meter, varieties of sensors were connected to the test rig where the temperature was measured at different locations. Temperature sensors and pressure transmitters that are connected to a form of data logger that records data every second. The isotherms and kinetics of the various adsorbents used have been tested at a certain temperature range.

\section{B. Adsorption process}

Seawater pumped intermittently into evaporator; pressure monitored and liquid phase will change into vapour. Evaporator opens to enable the vapour to escape through valves and adsorbed by the unsaturated adsorbent, which insulated the fins located inside the heat exchanger reactor bed. The brine occasionally discharged from the evaporator, when the valve between adsorption bed and evaporator open, a continuous vapour uptake achieved.

\section{Adsorption desorption process}

The most important part of the study is adsorption-desorption process in reactor, all tests are based on that column. The process in reactor is divided into two cycles. The first cycle is adsorption and the second cycle is desorption. Adsorption cycle takes place when the water circulating in the reactor bed cold and that lead to adsorbent material to have hydrophilic properties it then adsorb (attract) the vapour. In desorption cycle, hot water circulate in the reactor bed and that lead to vapour rejection. Adsorbent material become hydrophilic and water vapour get desorbed (rejected). After desorption process, the vapour move to the condenser column and that is where the 
water vapour condense into fresh water. The whole cycle takes place in adsorption equilibrium. Fig. 3 below, represent adsorption desorption process:

Adsorption (Discharge)

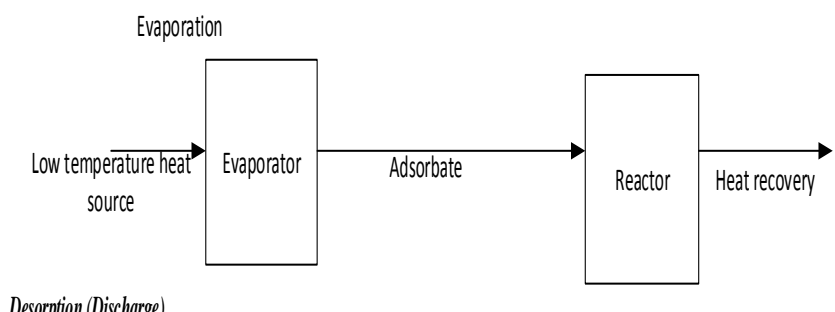

Desorption (Discharge)

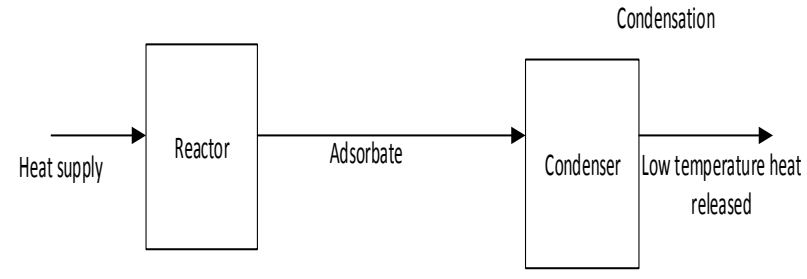

Fig. 3: adsorption desorption process

\section{Adsorption equilibrium}

After a long period of time when adsorbing molecules settled on adsorbent surfaces, the equilibrium state achieved [10]. The amount of adsorbents accumulated at equilibrium on the adsorbent surface known as equilibrium adsorption [10]. At the point when a vapour adsorbed onto a formerly empty strong surface or its pore space, the measurements of the vapour adsorbed is relative to the strong mass [10]. The vapour up-take additionally relies upon temperature $(\mathrm{T})$, the equilibrium partial weight of the pressure $(\mathrm{P})$, and the idea of the strong and vapour. For a vapour adsorbed on a strong at a fixed temperature, the adsorbed amount per unit mass of the strong $(\mathrm{Q})$ is then just a component of $\mathrm{P}[10]$.

\section{DISCUSSION}

\section{A. Comparative performance of adsorbents}

With regards to this context, most authors concentrated on adsorbent adsorption temperature control theoretical and technological improvements. Several accomplishments have been made and widely reported through their great efforts. However, there is no much information on literature that state which adsorbent perform at best in adsorption desalination, hence there is a need for a study to be conducted to close the gaps in the literature by analysing and comparing the adsorbent to find the one that is suitable for thermal desalination.

This section looks closely to the performance of the three previously defined adsorbents i.e. silica gel, Natural molecular zeolite and activated alumna. In addition it furthermore compare the results found by other researchers from the literature in order to gain an understanding in finding out which adsorbent perform at best.
$\mathrm{Ng}$ at el. [17] have investigated the use of silica gel and its life cycle cost analysis, with two useful effects generated through an $\mathrm{AD}$ cycle, namely high-quality drinking water and cooling energy, a fair manner of comparison is between the cycle and the processes or machines that could provide the same amount of useful effects [17].. For an AD process with an adsorbent stock of $1000 \mathrm{~kg}$ silica gel, $\mathrm{Ng}$ at el., [17] continue state that the value of the two beneficial effects under calculated conditions is $12.5 \mathrm{~m}^{3} /$ day of drinking water level [17].

A prepared silica gel with monitored dehydration by coagulation of colloidal silica acid solution used [17]. Silica gel avoids almost all water vapour at lower regeneration temperatures and provides hydrophobic qualities [17]. Because of hydrophilic (adsorb) and hydrophobic (reject) behaviours, Silica gel is labelled as active adsorbent for water cooling applications; regeneration temperatures, in general, are low in comparison to other adsorbents [17].

The basic action of silica gel vapor absorption is the physical adsorption due to the van der Waals forces and the electrostatic force between the adsorbed molecules and the surface atoms [17]. This employs a silica gel and water adsorbent-adsorbate combination. The basic working principles of an $\mathrm{AD}$ cycle focus on the optimal adsorption of water vapor by the chemical potential of an unsaturated adsorbent (silica gel) in a half-cycle time when the same adsorbent can be regenerated later in the next half-cycle by heating it with a low-temperature source of heat, standard heat source temperatures from $50^{\circ} \mathrm{C}$ to $85^{\circ} \mathrm{C}$ [17].

$\mathrm{Ng}$ at el.,[17] continued stating that a fusion reactor with a nominal water production capacity of $12.5 \mathrm{~m}^{3}$ per ton of silica gel per day and a cooling potential of 24 tons of cooling (Rtons) at $85^{\circ} \mathrm{C}$ for the heating element, $30^{\circ} \mathrm{C}$ for the cooling water and $7{ }^{\circ} \mathrm{C}$ for the cooling water. [17]. Water production levels and cooling capacity increase directly with an increase in cooling water temperature, but these input costs may decrease with higher coolant temperatures [17].

$\mathrm{Wu}$ at el., [26] experimentally tested silica gel using two-reactor bed heat exchangers in adsorption based, which is the most common method of most practicable production system and develop a model to compare both adsorbent temperature distribution and water profile obtain experiment, with the aim of reporting a detailed study of the effect of efficiency on the profitability of the water system and specific energy consumption is to be published.

The development of potable water in a certain period of time is a fundamental element in defining a silica gel performance [26]. The cycle time used is between $4000 \mathrm{~s}-10^{5} \mathrm{~s}$ and it has been found that the adsorption temperature required is $20^{\circ} \mathrm{C}$ and silica gel bed is maintained at $80^{\circ} \mathrm{C}$ in order to initiate water desorption [26].

$\mathrm{Wu}$ at el, [26] Mr Wu said the study of these cycles indicated the best product when the temperature of the evaporator was higher than the temperature of the fluid used to cool the silica gel in the reactor bed and condenser[26]. Model data suggest that water production per cycle usually decreases during the first 
few cycles before a steady value is assumed, this decrease is due to insufficient silica gel desorption of water. The energy cost of heat over process of evaporation to condensation is estimated to be using $830 \mathrm{kWh} / \mathrm{m}^{3}$ in production of water [26].

Based on the material properties of the adsorbent itself, the adsorption efficiency of the thermal energy system varies. Lim at el., [15] conducted a study in a laboratory-scale adsorption system and measured desorption quality of two adsorbents in the same system to compare the adsorption output between adsorbents [15].

The desorption energy densities calculated were lower than the results of the comparison- silica gel: $442.8 \mathrm{~J} / \mathrm{g}$ zeolite 13X/4A: 1080 to $1289 \mathrm{~J} / \mathrm{g}$ [15]. The explanation for the above disparity is that while the same product is used, depending on the supplier and the production process, there may be a difference in property [15].

Lim at el., [15] states that water absorption increases with thermal storage in all test cases: around $12 \%$ to $17 \%$ in the silica gel sample, $11.5 \%$ to $15.5 \%$ in the zeolite $13 \mathrm{X}$ test, and $8.5 \%$ to $12.5 \%$ in the zeolite $4 \mathrm{~A}$ test [15]. Such findings are directly related to the maintenance by thermal storage of low reactor temperatures.

Every adsorbent shows a distinction in the energy storage density ratio to SDT-measured material energy density. The silica gel, zeolite $13 \mathrm{X}$, and zeolite $14 \mathrm{~A}$ ratio is $47 \%, 26 \%$, and $22 \%$, respectively [15]. The density of energy storage calculated in the current experiment shows a superior result compared to previous studies: silica gel: $120 \mathrm{MJ} / \mathrm{m} 3$; zeolite 13X: 208.1 MJ / m3. Particularly, the silica gel energy storage density in the current system shows a remarkably enhanced result compared to other experiments in the studies [15].

Regardless of all the initiatives published in references from the above-mentioned papers, there is considerable framework for improving the performance of the adsorbent used to speed up the process of adsorption-desorption and to have a high-quality affinity. Giving regard to the authors of this paper, a better adsorbent can be accomplished by the enhancement in finding the actual adsorbent with the right surface area to adsorb vapour, good porosity, high adsorption affinity and a longest life span.

The adsorption of the thermal energy and technical feasibility of produced fresh water depends on adsorbent's material properties; therefore it is important to evaluate the performance of adsorbents. Hence, why adsorbents are most needed components when working on a designed adsorption desalination system, because they serve as catalysts (speeding up the process of desalination) and increase the water production. In addition, the primary requirements for a system of financial separation are an adsorbent with reasonably high quality, power, and long life span. Selection of an optimal adsorbent for a desired application identified by relevant properties that the desired adsorbent should have.

\section{CONCLUSION}

A comprehensive review based on current adsorption processes and their performance has been done with an intention of producing an efficient adsorption desalination using an affordable solid vapour adsorbent. This is done by comparing the quantity of water uptake in each adsorbent tested in literature. The adsorption cycle was optimized based on different adsorbent types used. The optimum cycle time for a given adsorption cycle was determined under given conditions. Additionally, the adsorbent material reaction rate of kinetics and adsorbent capacity was determined.

From literature, the applications of three adsorbents in water purification were moderately reviewed. Nevertheless, studies show that the performance of these adsorbents relies on a number of features such as: capacity of the adsorbent, surface area, adsorption capacity, operating temperature and pressure range, equilibrium isotherm, kinetics, and the method of sorbent regeneration.

The selection of a reasonable adsorbent for a process of adsorption is a complex issue. For prediction of adsorbent material performance, depend on the test done in lab and the highest performing adsorbent selected as the best suitable adsorbent for adsorption desalination. There are many physical and chemical properties of the adsorbent; furthermore, a variation in either isothermal kinetics or adsorption equilibrium relies on most selection criteria. Low kinetics and low adsorbent strength content is less suitable than a strong adsorbent and fast kinetics adsorbent.

From the information gathered in this analysis it can be concluded that, due to the difference in the energy density of the material itself, the temperature increase in the zeolite materials is higher than silica gel during the adsorption reaction. It is noted that the Zeolite 13X has the highest density of thermal energy storage by unit mass based on adsorption.

While the high conductivity of silica gel materials in the adsorption reactor allows for efficient thermal distribution and efficiency in thermal storage. Thanks to its thermal features and improved device structure, the silica gel heat storage density of the experimental test results found by Lim at el., [20] was estimated to be much higher in mathematical modeling than the actual results found in lab.

$\mathrm{Ng}$ at el., [17] compared different cooling and desalination systems and reported the silica gel adsorption desalination system as one of the most expense-effective adsorbent and environmentally sustainable for adsorption. Furthermore, adsorption desalination utilise low energy $\left(<120^{\circ} \mathrm{C}\right)$ for test that made by $\mathrm{Ng}$ it shows that silica gel-water adsorption is one such solution that consumes minimal electricity as it replaces the energy-intensive mechanical that mainly requires heat as input.

The literature state that molecular sieve zeolite adsorb moisture more intensely than either silica gel or activated alumina. Silica gel has desorption temperature of $55-140^{\circ} \mathrm{C}$, activated alumina has a desorption temperature of $120-260^{\circ} \mathrm{C}$ and the molecular sieve zeolite has a desorption temperature 
that ranges between $175-370^{\circ} \mathrm{C}$. As much as zeolite has an excellent adsorptive capacity, it cannot be taken as the best adsorbent because it requires more energy to trigger the desorption process.

Therefore silica gel has A good chances of being a best adsorbent, it can easily release the vapour (lose some of adsorbing capacity) once the temperature start rising up, unlike a molecular sieve zeolite with uniform structure. It is also incredible active at temperatures below $25^{\circ} \mathrm{C}$, is non-corrosive and non-toxic nature.

\section{REFERENCES}

[1] Baerlocher, C., McCusker, L.B. and Olson, D.H., 2007. Atlas of zeolite framework types. Elsevier.

[2] Barker, F. and Basso, N., Aventis Pharma Ltd, 2004. Adsorbents and uses thereof. U.S. Patent Application 10/847,550.

[3] Bundschuh, J., Ghaffour, N., Mahmoudi, H., Goosen, M., Mushtaq, S. and Hoinkis, J., 2015. Low-cost low-enthalpy geothermal heat for freshwater production: Innovative applications using thermal desalination processes. Renewable and Sustainable Energy Reviews, 43, pp.196-206.

https://doi.org/10.1016/j.rser.2014.10.102

[4] Chandrashekara, M. and Yadav, A., 2017. Water desalination system using solar heat: a review. Renewable and Sustainable Energy Reviews, 67, pp.1308-1330.

https://doi.org/10.1016/j.rser.2016.08.058

[5] Dashtban, M. and Tabrizi, F.F., 2011. Thermal analysis of a weir-type cascade solar still integrated with PCM storage. Desalination, 279(1-3), pp.415-422

https://doi.org/10.1016/j.desal.2011.06.044

[6] Dubey, S.P., Gopal, K. and Bersillon, J.L., 2009. Utility of adsorbents in the purification of drinking water: a review of characterization, efficiency and safety evaluation of various adsorbents. J. Environ. Biol, 30(3), pp.327-332.

[7] Gálvez, J.B., García-Rodríguez, L. and Martín-Mateos, I., 2009. Seawater desalination by an innovative solar-powered membrane distillation system: the MEDESOL project. Desalination, 246(1-3), pp.567-576. https://doi.org/10.1016/j.desal.2008.12.005

[8] Gude, V.G., Nirmalakhandan, N., Deng, S. and Maganti, A., 2012. Low temperature desalination using solar collectors augmented by thermal energy storage. Applied Energy, 91(1), pp.466-474. https://doi.org/10.1016/j.apenergy.2011.10.018

[9] Guillén-Burrieza, E., Blanco, J., Zaragoza, G., Alarcón, D.C., Palenzuela, P., Ibarra, M. and Gernjak, W., 2011. Experimental analysis of an air gap membrane distillation solar desalination pilot system. Journal of Membrane Science, 379(1-2), pp.386-396.

https://doi.org/10.1016/j.memsci.2011.06.009

[10] Hübschmann, H.J., 2015. Handbook of GC-MS: fundamentals and applications. John Wiley \& Sons.

https://doi.org/10.1002/9783527674305

[11] Israelachvili, J.N., 2015. Intermolecular and surface forces. Academic press.

[12] Khayet, M., 2013. Solar desalination by membrane distillation: Dispersion in energy consumption analysis and water production costs (a review). Desalination, 308, pp.89-101. https://doi.org/10.1016/j.desal.2012.07.010

[13] Langenecker, B. and Zeilinger, C.E., Globe Protect Inc, 2010. Method and apparatus for desalination of seawater. U.S. Patent 7,770,830.

[14] Li, A., Thu, K., Ismail, A.B., Shahzad, M.W. and Ng, K.C., 2016. Performance of adsorbent-embedded heat exchangers using binder-coating method. International journal of heat and mass transfer, 92, pp.149-157. https://doi.org/10.1016/j.ijheatmasstransfer.2015.08.097

[15] Lim, K., Kim, J. and Lee, J., 2019. Comparative study on adsorbent characteristics for adsorption thermal energy storage system. International Journal of Energy Research. https://doi.org/10.1002/er.4553
[16] Mitra, S., Srinivasan, K., Kumar, P., Murthy, S.S. and Dutta, P., 2014. Solar driven adsorption desalination system. Energy Procedia, 49, pp.2261-2269. https://doi.org/10.1016/j.egypro.2014.03.239

[17] Ng, K.C., Thu, K., Kim, Y., Chakraborty, A. and Amy, G., 2013. Adsorption desalination: an emerging low-cost thermal desalination method. Desalination, 308, pp.161-179. https://doi.org/10.1016/j.desal.2012.07.030

[18] Plee, D. and Methivier, A., Carbonisation et Charbons Actifs (CECA) SA and IFP Energies Nouvelles, 2005. Agglomerated zeolitic adsorbents, method for obtaining same uses thereof. U.S. Patent 6,884,918.

[19] Ranjan, K.R., Kaushik, S.C. and Panwar, N.L., 2016. Energy and exergy analysis of passive solar distillation systems. International Journal of Low-Carbon Technologies, 11(2), pp.211-221. https://doi.org/10.1093/ijlct/ctt069

[20] Rouquerol, J., Rouquerol, F., Llewellyn, P., Maurin, G. and Sing, K.S., 2013. Adsorption by powders and porous solids: principles, methodology and applications. Academic press.

[21] Shahzad, M.W., Ng, K.C., Thu, K., Saha, B.B. and Chun, W.G., 2014. Multi effect desalination and adsorption desalination (MEDAD): A hybrid desalination method. Applied Thermal Engineering, 72(2), pp.289-297. https://doi.org/10.1016/j.applthermaleng.2014.03.064

[22] Sharshir, S.W., Peng, G., Yang, N., Eltawil, M.A., Ali, M.K.A. and Kabeel, A.E., 2016. A hybrid desalination system using humidification-dehumidification and solar stills integrated with evacuated solar water heater. Energy conversion and management, 124, pp.287-296. https://doi.org/10.1016/j.enconman.2016.07.028

[23] Sivarajasekar, N., Paramasivan, T., Muthusaravanan, S., Muthukumaran, P. and Sivamani, S., 2017. Defluoridation of water using adsorbents-a concise review. Journal of Environment \& Biotechnology Research, 6(1), pp.186-198.

[24] Wang, S. and Peng, Y., 2010. Natural zeolites as effective adsorbents in water and wastewater treatment. Chemical Engineering Journal, 156(1), pp.11-24. https://doi.org/10.1016/j.cej.2009.10.029

[25] Worch, E., 2012. Adsorption technology in water treatment: fundamentals, processes, and modeling. Walter de Gruyter. https://doi.org/10.1515/9783110240238

[26] Wu, J.W., Biggs, M.J., Pendleton, P., Badalyan, A. and Hu, E.J., 2012. Experimental implementation and validation of thermodynamic cycles of adsorption-based desalination. Applied energy, 98, pp.190-197. https://doi.org/10.1016/j.apenergy.2012.03.022

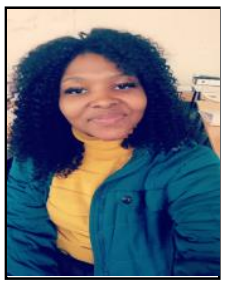

Sindisiwe Ntsondwa serves as a research student scientist at Cape Peninsula University of Technology as well as temporarily assisting at BAB Developers private college as a temporal junior facilitator. She acquires a National diploma and Bachelor of Technology in chemical engineering. She's currently enrolled at CPUT pursuing Master's degree in Chemical engineering under the wastewater treatment. In working together with Dr Msomi, Dr Basitere and Zamavangeli Mdletshe in order to address analysis and processing environmental acoustics for adsorption desalination process. Sindisiwe Ntsondwa is an avid supporter of the belief that throughout desalination we can quench or improve the worldwide water crises, while using a method that does not utilise lot of energy and at the same time environmental friendly. 